\title{
EFFECTS OF CRISIS COMMUNICATION STRATEGIES AND MEDIA REPORT ON CORPORATE IMAGE IN CATERING INDUSTRY
}

\author{
Sri GUNAWAN ${ }^{1}-$ Chich-Jen SHIEH ${ }^{2}-\mathrm{Yu} \mathrm{PEI}^{3}$ \\ ${ }^{1}$ Department of Management, Airlangga University, Indonesia, Jalan Air-langga No. 4 Surabaya, \\ 60286 Indonesia.E-mail: sgunawan@feb.unair.ac.id \\ ${ }^{2}$ Department of International Business at Chang Jung Christian University, Taiwan, No. 1, \\ Changda Rd. Gueiren District, Tainan City 71101, Taiwan.E-mail: Charles@mail.cjcu.edu.tw \\ ${ }^{3}$ School of Public Economics, Nanjing Audit University, Zhonghe Building, 86 West Yushan Road, \\ Pukou District, Nanjing, China.E-mail: peiyu@nau.edu.cn (corresponding author)
}

The enhancement of economic development and living standard in last years has the people stress more on recreational life that tourism becomes prevalent in Taiwan. County and city governments positively promote tourism and hold cultural festivals to enhance the boom of accommodation and catering industries and further fire national tourism market and catering industry.

Through online questionnaire survey, the customers of Wang Steak, TASTy, Tokiya, and ikki, which are the subsidiaries of Wowprime and burst out the oil scandal recently, are distributed 800 copies of questionnaires. Total 388 effective copies are retrieved with the effective rate $49 \%$. The research results are concluded as follows. 1. Crisis Communication Strategies would affect Media Report. 2. Crisis Communication Strategies would influence Corporate Image. 3. Media Report has significantly positive effects on Managerial Capacity in Corporate Image. 4. Media Report presents remarkably positive effects on Corporate Reputation in Corporate Image. 5. Media Report shows notably positive effects on Communication News in Corporate Image. It is expected that catering businesses could enhance the countermeasures of Crisis Communication Strategies to cope with crises.

Keywords: catering industry, Crisis Communication Strategies, Media Report, Corporate Image

\section{INTRODUCTION}

In the $21^{\text {st }}$ century, enormous changes and transformation are happening globally. The rapid development of information technology and the complexity of societies allow information flowing rapidly in the global structure as well as change traditional risks. For instance, the increasing occurrence and severity of crises, such as financial crisis, international price index, price fluctuation of raw materials, and price adjustment of enterprises, not only present the high uncertainty 
and insecurity in modern risky societies, but the impact and influence on societies could also be expanded because of the public innocence and panic at such events. An enterprise or organization therefore might encounter a following crisis anytime. Moreover, crises being non-confidential resulted from the monitoring of media in the external environments and the expanding report of agendas could inevitably endanger corporate image and sales volume.

Nonetheless, food is essential for people; either fresh food or eating out is closely related to life. In recent years, digital media and mobile network even cause the easy acquisition of information so that people are stepping towards the era of global village and internationalization becomes the final trend of an enterprise. The same conditions occur in catering industry, in which consumers often make online enquiries and comparisons through the powerful network seeking function and observe the marketing environment to present the sensitivity to prices and the haggling attitudes. Catering industry is a part of service industries that it is important to maintain favorable customer relationship. Besides, it is wondered how to deal with crises when crises occur in catering industry. The crisis communication strategies and the maintenance of corporate image are the key discussions in this study.

\section{LITERATURE REVIEW}

\subsection{Crisis Communication Strategies}

Byrne (2010) defined crises as major events resulting in potential negative effects on an organization, enterprise, or industry and influencing the public, product, service, or reputation of the organization to impact the normal operation of an organization and even threatened the survival of the organization. Coombs and Holladay (2010) considered that a lot of researchers started to explain crises from general aspects and regarded the occurrence of crises as the necessary stage in the development of an organization so that a crisis was a threat as well as an opportunity for an organization. According to Kaur and Soch (2012), three standards were proposed to determine the occurrence of a crisis. 1. Suddenness. A crisis presented explosiveness and impact, and the great damage caused the agent having no time to respond and even lose the responsive capacity. 2. Menace. Immediate and obvious threats to the survival and development of an organization could result in huge life and property losses if not being immediately removed. 3. Short decision-making time. The major test of crises for an agent is to make decisions 
in extremely nervous situations and allow the decision-making time being short. Louisville (2013) proposed four characteristics of crisis, including 1. crises with an important turning point to develop distinct results of the event. 2 . being necessary to make certain decisions, 3 . at least a major value being threatened, and 4. making a decision under time pressure.

Crisis Communication Strategies are used for reducing crisis damage, recovering or reconstructing organizational image, and further affecting the responses of a stakeholder to various crisis responsibilities (Meng 2010). Russell and Pamela (2010) were the first researchers proposing the explanation and predictive model for crisis communication, attempting to overall analyze the case and find out the explanation of "more effective strategies in different situations" (Von Riesen and Herndon 2011). In simplicity, when an enterprise or a governmental organization adopted image repair strategies, crises were the direct effect and the key success factor in such strategies (Collado Agudo et al. 2012). Shih (2012) investigated the public relation practitioners of top 500 enterprises in Taiwan and proposed five major Crisis Communication Strategies and the sub-strategies.

1. Denial. Denying the occurrence or existence of an event or a person as the cause of an event, where simple denial was the sub-strategy.

2. Excuse. Emphasizing some factors in limiting the accused controlling the occurrence or effects of an event so that they did not need to be responsible for such an event (attempting to avoid responsibilities).

3. Justification. Declaring the accused being more or less responsible for adverse events, but the standard, which an accuser used for measuring or criticizing the effects of an event, being inappropriate.

4. Concession. The intention to admit accusation and apology, adopt correction, compensation, reinforcement of future prevention, and change of public policies of an enterprise as well as to provide adaptive or instructive information.

5. Diversion. "Stopping" or dispersing the attention of the public and the media by creating new agendas, or expressing regret to calm down the public anger (but not to apologize).

\subsection{Media report}

Claeys and Cauberghe (2012) mentioned that the media constructed the external impression of people; the authenticity of a crisis became unimportant after people's perception was controlled; and, the importance was how the media reported such an event (Demetriou et al. 2010). Ki and Brown (2013) pointed out the media as a crisis observer that the opinions of media about specific events could easily change the public opinions about the organization and the management team. 
Media report would build people's perception and evaluation of events, which was the same when a crisis occurred in an enterprise. When there were major crises occurring in an enterprise or an organization, the media became a stage for profit exchange. Various profit groups strived for the right of speech to maintain the profit (McDonald et al. 2010). Referring to Peloza and Shang (2011), Media Report is discussed from three dimensions in this study.

1. Major Source of News. When a crisis bursts out, the media require large amount of information sources. The information announced by an enterprise shows the presentation of Crisis Communication Strategies on the media being favorable, which is the expected result of an enterprise (Schakett et al. 2011).

2. Evaluation to Reports. Mass media present the agenda setting effect of a crisis that the perceived evaluation of a stakeholder to corporate crisis depends on the agenda setting and the frame report of the media (Xu and Li 2013). In other words, a crisis being positively reported by the media shows the high effectiveness of Crisis Communication Strategies of the enterprise.

3. Evaluation of Reporters. Starting from the burst of a crisis, a reporter focuses on the entire evaluation of the communication strategies applied by the enterprise to the crisis, including the past impression of the enterprise and the comment of the mass society on the crisis, in the interview. When the entire evaluation is high, the successive reports would be positive; otherwise, negative reports would be continued (Collado et al. 2012).

\subsection{Corporate Image}

Corporate Image indicates the total acquaintance and evaluation of the mass society about an enterprise that it presents the psychological activities of the public as well as an enterprise deepening the image, reinforcing the attitudes, and forming the public opinions in the society (Claeys et al. 2010; Xu and Shieh 2014). Elliot (2010) found out the loss of reputation being the major damage to an enterprise and indicated that maintaining favorable image was a serious issue in various industries. Corporate crisis being exposed through the media would damage Corporate Image and cause Image Crisis of the enterprise (Kim and Niederdeppe 2013). There were lots of measuring indicators for Corporate Image. For example, Fatima Oliveira (2013) had the participants evaluate Corporate Image with 45 personality variables and extracted 6 independent factors with Factor Analysis (Percy 2010), covering Dynamic, showing the positive and active spirit, flexibility, and leadership of a company, Co-operation, presenting the friendliness, clear atmosphere, and self-dignity of a company, Business Wise, revealing an enter- 
prise being quick, smart, persuasive, and presenting favorable organizational system, Corporate Character, referring to an enterprise focusing on the reputation, being respectful, and showing business ethics, Corporate Success, presenting the financial and business performance of an enterprise, and Withdrawn, showing the risky spirit of an enterprise. Schultz et al. (2011) divided Corporate Image into 1. institution image, the mass regarding a company as a whole and an enterprise as a member of the society, including corporate image and store image, 2. functional image, the image generated from the operational activities in an enterprise management, containing service image and price image, and 3. commodity image, the attitudes of people towards the commodities or services provided by a company, covering brand image and product image.

Referring to Stading and Johnson (2012), who organized the public perceived risks, the following dimensions are constructed to evaluate Corporate Image in this study.

1. Managerial Capacity. Regardless of single even or continuous events, a crisis could threaten the legal status of an organization and is the key factor in the continuous survival of an organization (Zhang 2010). For instance, several serious incidents on China Airlines years ago resulted in the public doubting the legitimacy of the managerial capacity, skill, and structure as well as the unease and danger for the public (Vandana and Ashish 2014).

2. Corporate Reputation (reliability/honest/trusty). Piotrowski and Guyette (2010) indicated that the public could accept an organization admitting the mistake and give chances; however, the unpredictable comments and lack of overall planning could result in the loss of trust and not believing that the organization would take the responsibility. As most risk agendas are related to human health, the influence time and range are deeper that not only are ethic problems related, but the public anger and blame are likely aroused. For example, Johnson \& Johnson successfully dealt with The Tylenol Poisonings by recovering the consumer confidence; Intel, on the other hand, failed in the crisis of chip defects as it could not recover the consumer confidence (Demetriou et al. 2010).

3. Communication News. Peloza and Shang (2011) indicated that good communication relied on an organization offering complete risk situations and background knowledge so that the public could participate in the dialogues and indirectly join in the crisis decision-making process. When a crisis occurs, two-way communication between the organization and the public is necessary to acquire the public trust by putting public safety and organizational profits on the equal position (Von Riesen and Herndon 2011). In other words, open and transparent communication processes, definite decisions, and public participation are the key factors in the public perception (Groza et al. 2011). 


\subsection{Research hypothesis}

Mass media presents the characteristics of agenda setting and frame report. After screening the news, the news characteristics and the reporting styles are largely changed. When the public is not close to the media, the comprehension of events would be affected by the frame of media reports (Collado Agudo et al. 2012). An enterprise uses crisis strategies for reducing damage caused by crises and recovering the image (Shieh 2014). However, regardless of the mistake of an organization, the stakeholders insist that the organization should be responsible for the crisis, and the organization has to release the crisis and recover the organizational image as much as possible (Groza et al. 2011). Media reports would affect personal perception of an event. For instance, the rising food price after typhoon is closely related to the public; however, it might not be so much emphasized without the lengthy report of the media. Piotrowski and Guyette (2010) stated that the healthy information in the media would unintentionally result in positive or negative effects on the audience. Furthermore, news report of health, though without direct intention, would present critical and permanent effects, and the range would cover health, behaviors, and policies. When facing risks, society could learn the communication in the public statement and the daily information delivery among experts from different fields and the layman to gradually grasp the outline of risk knowledge (Shabbir et al. 2010). Utz et al. (2013) indicated that the longer crisis induction period of an enterprise would accumulate larger energy, especially for large enterprises, as they receive larger concerns and pressure from public opinions. The lengthy reports from the media would result in the emphases and concerns of the society. In a risk society, mass media become a critical part in risk knowledge (Vandana and Ashish 2014). The following hypotheses are therefore established in this study.

H1: Crisis Communication Strategies would affect Media Report.

H2: Crisis Communication Strategies would influence Corporate Image.

H3: Media Report presents significantly positive effects on Managerial Capacity in Corporate Image.

H4: Media Report reveals remarkably positive effects on Corporate Reputation in Corporate Image.

H5: Media Report shows notably positive effects on Communication News in Corporate Image. 


\section{RESEARCH METHOD}

\subsection{Research framework}

Summing up the above literature review, the conceptual framework (Figure 1) is drawn up to discuss the relations among Crisis Communication Strategies, Media Report, and Corporate Image.

\subsection{Measurement of research variable}

\section{Media Report}

Referring to Peloza and Shang (2011), Media Report is divided into three dimensions of (1) Major Source of News, (2) Evaluation of Reports, and (3) Evaluation of Reporters.

2. Corporate Image

Referring to Stading \& Johnson (2012), the following dimensions are covered, including (1) Managerial Capacity, (2) Corporate Reputation, and (3) Communication News.

\subsection{Research subject and sampling data}

Wowprime, established in 1990, is selected as the research subject. The first subsidiary, Wang Steak, was opened in Taichung City and was famous of the marketing tactic of merely 6 serves of steak being made from a cow. The Multiple Brand Management has the subsidiary enterprises of Wowprime develop the strengths.

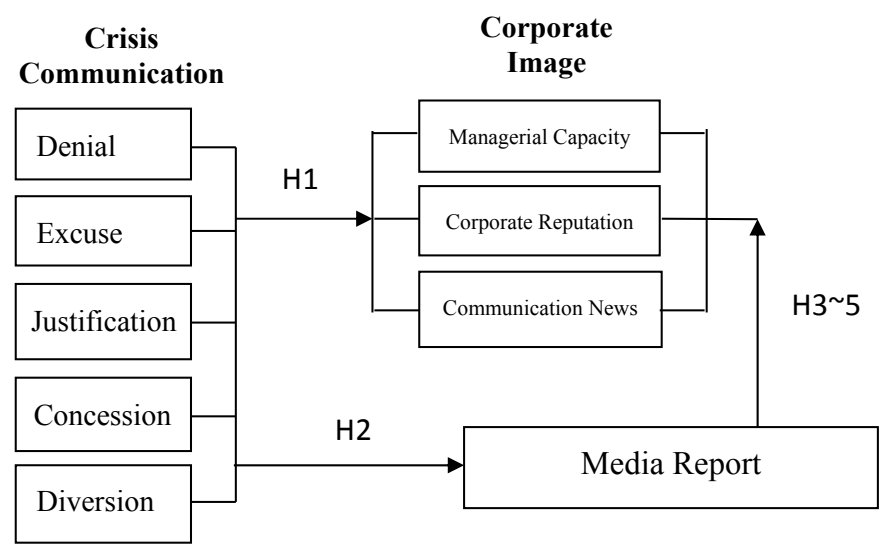

Figure 1. Research framework 
To guarantee the brand management, a series of standardized rules are formulated to assist in the management of internal brands and help each brand create better performance with research and development, marketing placement, human resources, and information system. Since the openness of the first Wang Steak in 1993, the annual revenue has broken through five billion dollars that it becomes the number-one enterprise group in catering industry in Taiwan. The key success of Wowprime lies in the human-based corporate culture created by the chairman, Sheng-yi Dai, and the vice president, Kuo-hsiung Wang. From "Familism", based on which the employees are taken good care with sincere concerns, to the complete and detailed education training and lifelong learning, the creative inner culture is encouraged and even the opportunity of internal corporate entrepreneurship for the employees is offered, allowing a waiter/waitress could become an owner. The impressive subsidiaries of Wowprime contain Wang Steak, TASTy, Tokiya, Yakiyan, Hokkaido, ikki, Chamonix, Pinnada, Hotpot, Sufood, and ita(pizza). With online questionnaire survey, the customers of Wang Steak, TASTy, Tokiya, and ikki, the subsidiaries of Wowprime which burst out the oil scandal recently, are sampled. Total 800 copies of questionnaires are distributed, and 388 effective ones are retrieved, with the effective rate 49\%; each copy of questionnaire is regarded as a valid sample. The data are analyzed with SPSS, and Factor Analysis, Reliability Analysis, Regression Analysis, and Analysis of Variance are utilized for testing the hypotheses.

\subsection{Analysis}

Analysis of Variance is used for discussing the variance of Crisis Communication Strategies to Media Report and Corporate Image, and Regression Analysis is further applied to understanding the relations between Media Report and Corporate Image.

\section{ANALYSIS RESULT}

\subsection{Reliability and Validity Analyses}

With Factor Analysis, Media Report was extracted three factors of Major Source of News (eigenvalue $=2.166, \alpha=0.87$ ), Evaluation of Reports (eigenvalue $=$ $1.764, \alpha=0.81$ ), and Evaluation of Reporters (eigenvalue $=1.383, \alpha=0.84$ ). The accumulatively explained covariance achieved $75.824 \%$. 
With Factor Analysis, Corporate Image was extracted three factors of Managerial Capacity (eigenvalue $=2.483, \alpha=0.86$ ), Corporate Reputation (eigenvalue $=$ 2.175, $\alpha=0.82$ ), and Communication News (eigenvalue $=1.959, \alpha=0.88$ ). The accumulatively explained covariance reached $80.933 \%$.

\subsection{Effects of Crisis Communication Strategies on Media Report and Corporate Image}

\subsubsection{Variance Analysis of Crisis Communication Strategies to Media Report}

Analysis of Variance was utilized for discussing the variance of Crisis Communication Strategies to Media Report, i.e. analyzing and explaining Crisis Communication Strategies of Denial, Excuse, Justification, Concession, and Diversion. Table 1 shows the variance of Crisis Communication Strategies to Media Report, where Crisis Communication Strategies presented significant variance on Major Source of News, Evaluation of Reports, and Evaluation of Reporters.

Table 1. Variance Analysis of Crisis Communication Strategies to Media Report

\begin{tabular}{|c|c|c|c|c|}
\hline \multicolumn{2}{|c|}{ Variable } & $\mathrm{F}$ & $\mathrm{P}$ & Scheffe post hoc \\
\hline $\begin{array}{c}\text { Crisis Communi- } \\
\text { cation Strategies }\end{array}$ & $\begin{array}{c}\text { Major Source } \\
\text { of News }\end{array}$ & 16.523 & $0.006^{*}$ & $\begin{array}{c}\text { Denial, Diversion> Excuse, Concession, } \\
\text { Justification }\end{array}$ \\
\cline { 2 - 5 } & $\begin{array}{c}\text { Evaluation } \\
\text { of Reports }\end{array}$ & 8.376 & $0.012 *$ & $\begin{array}{c}\text { Justification, Concession, } \\
\text { Excuse }>\text { Diversion, Denial }\end{array}$ \\
\cline { 2 - 5 } & $\begin{array}{c}\text { Evaluation } \\
\text { of Reporters }\end{array}$ & 11.422 & $0.017 *$ & $\begin{array}{c}\text { Justification, Concession, } \\
\text { Excuse }>\text { Diversion, Denial }\end{array}$ \\
\hline
\end{tabular}

* stands for $\mathrm{p}<0.05$

\subsubsection{Variance Analysis of Crisis Communication Strategies to Corporate Image}

Analysis of Variance was applied to exploring the variance of Crisis Communication Strategies to Corporate Image, i.e. analyzing and explaining Crisis Communication Strategies of Denial, Excuse, Justification, Concession, and Diversion. Table 2 shows the variance of Crisis Communication Strategies to Corporate Image, where Crisis Communication Strategies appeared remarkable variance on Managerial Capacity, Corporate Reputation, and Communication News. 
Table 2. Variance Analysis of Crisis Communication Strategies to Corporate Image

\begin{tabular}{|c|c|c|c|c|}
\hline \multicolumn{2}{|c|}{ Variable } & $\mathrm{F}$ & $\mathrm{P}$ & Scheffe post hoc \\
\hline $\begin{array}{c}\text { Crisis Communi- } \\
\text { cation Strategies }\end{array}$ & Managerial Capacity & 15.416 & $0.032 *$ & $\begin{array}{c}\text { Justification, Concession, } \\
\text { Diversion> Excuse, Denial }\end{array}$ \\
\cline { 2 - 5 } & Corporate Reputation & 22.738 & $0.000 *$ & $\begin{array}{c}\text { Justification, Concession>Excuse, } \\
\text { Diversion, Denial }\end{array}$ \\
\cline { 2 - 5 } & Communication News & 37.163 & $0.000 *$ & $\begin{array}{c}\text { Justification, Concession>Excuse, } \\
\text { Diversion, Denial }\end{array}$ \\
\hline
\end{tabular}

* stands for $\mathrm{p}<0.05$

\subsection{Correlation Analysis of Media Report and Corporate Image}

(1) Correlation Analysis of Media Report and Managerial Capacity

To test H3, the analyses, see Table 3, revealed the remarkable effects of Major Source of News $\left(\beta=1.532^{*}\right)$, Evaluation of Reports $\left(\beta=1.836^{*}\right)$, and Evaluation of Reporters $\left(\beta=1.747^{*}\right)$ on Managerial Capacity that H3 was supported.

(2) Correlation Analysis of Media Report and Corporate Reputation

To test H4, the analyses, see Table 3, presented the notable effects of Major Source of News $\left(\beta=1.796^{*}\right)$, Evaluation of Reports $\left(\beta=2.104^{* *}\right)$, and Evaluation of Reporters $\left(\beta=2.063^{* *}\right)$ on Corporate Reputation that H4 was supported.

(3) Correlation Analysis of Media Report and Communication News

To test H5, the analyses, see Table 3, showed the notable effects of Major Source of News $\left(\beta=1.884^{*}\right)$, Evaluation of Reports $\left(\beta=2.247^{* *}\right)$, and Evaluation of Reporters $\left(\beta=2.125^{* *}\right)$ on Communication News that H5 was supported.

Table 3. Analysis between Media Report and Corporate Image

\begin{tabular}{|c|c|c|c|c|c|c|}
\hline Dependent variable $\rightarrow$ & \multicolumn{6}{|c|}{ Corporate Image } \\
\hline Independent variable $\downarrow$ & \multicolumn{2}{|c|}{ Managerial Capacity } & \multicolumn{2}{|c|}{ Corporate Reputation } & \multicolumn{2}{|c|}{ Communication News } \\
\hline Media Report & $\beta$ & Beta & $\beta$ & Beta & $\beta$ & Beta \\
\hline Major Source of News & $1.532 *$ & 0.121 & $1.796^{*}$ & 0.131 & $1.884 *$ & 0.163 \\
\hline Evaluation of Reports & $1.836^{*}$ & 0.152 & $2.104 * *$ & 0.186 & $2.247 * *$ & 0.212 \\
\hline Evaluation of Reporters & $1.747 *$ & 0.127 & $2.063 * *$ & 0.178 & $2.125 * *$ & 0.194 \\
\hline $\mathrm{F}$ & \multicolumn{2}{|c|}{18.461} & \multicolumn{2}{|c|}{24.982} & \multicolumn{2}{|c|}{31.279} \\
\hline Significance & \multicolumn{2}{|c|}{$0.000 * * *$} & \multicolumn{2}{|c|}{$0.000 * * *$} & \multicolumn{2}{|c|}{$0.000 * * *$} \\
\hline R2 & \multicolumn{2}{|c|}{0.257} & \multicolumn{2}{|c|}{0.294} & \multicolumn{2}{|c|}{0.323} \\
\hline Adjusted R2 & \multicolumn{2}{|c|}{0.023} & \multicolumn{2}{|c|}{0.027} & \multicolumn{2}{|c|}{0.030} \\
\hline
\end{tabular}

Note: $*$ stands for $\mathrm{p}<0.05, * *$ for $\mathrm{p}<0.01, * * *$ for $\mathrm{p}<0.001$

Data source: self-organized in this study. 


\section{CONCLUSION}

The research findings indeed present the remarkable effects of Crisis Communication Strategies on Corporate Image in catering industry. The brand management in catering industry should be clear of the orientation, emphasize the public consciousness, measure the perception of consumers before making any decisions, exhaustively prepare the public statement, communication \& corresponding strategies, and preventive measures in advance, deduce the preparation for crisis solution, and actively grasp the agenda. In the crisis handling process in catering industry, the authenticity of an event is not important, but the perceived truth of the public. The consumers would take empathy as a personal kindness. When a crisis occurs, the mass society would criticize the catering business with negatives and blame that the application of image recovery strategies in the communication is not simply to solve the current dilemma, but for the long-term development of the catering business.

As a consequence, a crisis could be calmed down by a catering business clearly explaining the reasons, product value, and market differentiation, or even building the brand affect, reducing crisis coverage, actively and rapidly communicating with the media, reducing the negative impression of the media and consumers, and shortening the media report. In such depression environments, the continuous sales promotion of catering businesses incandesce the market competition. Catering businesses therefore should often consider the communication information and permanently stress on the connection and communication with the media and consumers so as to help the crisis handling, and the communication when a crisis occurs.

\section{SUGGESTION}

Aiming at the above research results, the following suggestions are proposed in this study.

1. The public perceived risk of the event. Since most risks in catering industry directly involve in physical health, it is suggested that a catering business should investigate the public perception of the risk and understand the social public opinions to further draft Crisis Communication Strategies for reducing the damage caused by the crisis, positively keep good interaction with the media, appropriately communicate with the mass society to save the confidence, and reconcile the trust crisis. When the public perceive danger of a crisis, a catering business could apply low-justification Crisis Communication Strategies, such as Concession. Moreover, a catering business could better adapt to 
the customs and habits, observe the economic and political development, and conform to the media openness to revise the crisis communication strategies in order to conform to the contemporary demands.

2. Formulating consumer-centered Crisis Communication Strategies. Any catering businesses whose products damage consumer benefits should be responsible for the products and the consumers. To reconcile a crisis, a catering business should formulate consumer-centered Crisis Communication Strategies and avoid seeking instant profits. With rising consumer awareness, consumers become more active to protect the benefits. In sum, a catering business should communicate with consumers with humble attitudes to acquire the emotional identification so as to go through the crisis.

3. Increasing humorous materials in the characteristics. From the research result, the effects of the media cannot be ignored when a crisis suddenly occur in catering industry. To some extent, a crisis in catering industry is often resulted from the media report. Since the media play the role of a mediator between catering industry and the public, it is primary for a catering business making good relationship with the media. In this case, the media is the most important secondary stakeholder in a crisis, as the media report could affect the other stakeholders' opinions, meaning that the media play a critical role. In order to acquire positive and affirmative media assessment, a catering business, in addition to favorable Communication Strategies, has to continuously interact with the media.

\section{REFERENCES}

Byrne, B.B. (2010). Structural Equation Modeling Using AMOS. Basic concepts, Applications, and Programming. (2nd ed). New York: Routledge.

Claeys, A.S. and Cauberghe, V. (2012). What makes crisis response strategies work? The impact of crisis involvement and message framing. Journal of Business Research, 67(2), 182-189.

Claeys, A.S., Cauberghe, V. and Vyncke, P. (2010). Restoring reputations in times of crisis: an experimental study of the situational crisis communication theory \& the moderating effects of locus of control. Public Administration Review, 36, 256-262.

Collado Agudo, J., Herrero Crespo, A. and Rodríguez del Bosque, I. (2012). Adherence to customer loyalty programmes and changes in buyer behaviour. Service Industries Journal, 32(8), $1323-1341$.

Coombs, W.T. and Holladay, S.J. (2010). PR Strategy and Application: Managing Influence. West Sussex: Wiley-Blackwell.

Demetriou, Papasolomou and Vrontis (2010). Cause-related marketing: Building the corporate image while supporting worthwhile causes. Journal of Brand Management, 17, 266-278.

Elliot, J.D. (2010). How do past crises affect publics' perceptions of current events? An experiment testing corporate reputation during an adverse event. In W.T. Coombs and S.J. Holladay (Eds.), The Handbook of Crisis Communication. West Sussex: Wiley-Blackwell, 205-220.

Fatima Oliveira, M. de (2013). Multicultural environments and their challenges to crisis communication. Journal of Business Communication, 50(3), 253-277. 
Groza, Pronschinske and Walker (2011). Perceived organizational motives and consumer responses to proactive and reactive CSR. Journal of Business Ethics, 102(4), 639-652.

Kaur, H. and Soch, H. (2012). Validating antecedents of customer loyalty for Indian cell phone users. The Journal for Decision Makers, 37(4), 47-61.

Ki, E-J., Brown, K.A. (2013). The effects of crisis response strategies on relationship quality outcomes. Journal of Business Communication, 50(4), 403-420.

Kim, H.K. and Niederdeppe. J. (2013). The role of emotional response during an H1N1 influenza pandemic on a college campus. Journal of Public Relations Research, 25(1), 30-50.

Lee Moonkyu, Lee Hyoung-Tark and Kim Na-Min (2010). Corporate social responsibility and employee-company identification. Journal of Business Ethics, 95, 557-569.

Louisville, K.Y. (2013). The 2012 Annual ICM Crisis Report, Institute for Crisis Management Releases, June. Institute for Crisis Management, 22(1).

McDonald, L.M., Sparks, B. and Glendon, A.I. (2010). Stakeholder reaction to company crisis communication \& causes. Public Relations Review, 36, 263-271.

Meng, J. (2010). SK-2 China and its skin cream scandal: an extended analysis of the image restoration strategies in a non-Western setting. Public Relations Review, 36, 66-69.

Peloza and Shang (2011). How can corporate social responsibility activities create value for stakeholders? A systematic review. Journal of the Academy of Marketing Science, 39, 117-135.

Percy Marquinar (2010). The influence of corporate social responsibility on Peruvian's consumers purchasing behavior. Journal of Leadership, Accountability and Ethics, 8(2), 70-79.

Piotrowski, C. and Guyette, Jr. R.W. (2010). Toyota recall crisis: Public attitudes on leadership and ethics. Organization Development Journal, 28(2), 89-97.

Russell and Pamela (2010). Longitudinal effects of corporate social responsibility on customer relationships. Journal of Business Ethics, 97, 581-597.

Schakett, T., Flaschner, A., Gao, T. and El-Ansary, A. (2011). Effects of social bonding in businessto-business relationships. Journal of Relationship Marketing, 10(4), 264-280.

Schultz, F., Utz, S. and Goritz, A. (2011). Is the medium the message? Perceptions of \& reactions to crisis communication via twitter, blogs \& traditional media. Public Relations Review, 37, 20-27.

Shabbir, Kaufmann, Ahmad and Qureshi (2010). Cause related marketing campaigns and consumer purchase intentions: The mediating role of brand awareness and corporate image. African Journal of Business Management, 4(6), 1229-1235.

Shieh, C.J. (2014). The impacts of social network on operating performance in micro-enterprises. Acta Oeconomica, 64(Supplement 2), 229-242.

Shih, T.Y. (2012). Integrative effects of firms' price and endorsement strategies on consumers' loyalty intention. The Service Industries Journal, 34(6), 981-1005.

Stading, G.L. and Johnson, M. (2012). An examination of the relationship between a firm's offerings and different customer loyalty segments. Journal of Business-To-Business Marketing, 19(4), 367-391.

Utz, S., Schultz, F. and Glocka, S. (2013). Crisis communication online: How medium, crisis type and emotions affected public reactions in the Fukushima Daiichi nuclear disaster. Public Relations Review, 39(1), 40-46.

Vandana, M. and Ashish, M. (2014). Marketing ethics: conceptual study. International Research Journal of Management Sociology \& Humanities, 5(5), 448-453.

Von Riesen, R.D. and Herndon, N.C. (2011). Consumer involvement with the product and the nature of brand loyalty. Journal of Marketing Channels, 18(4), 327-352.

$\mathrm{Xu}$, Kaibin and Li, Wenqing (2013). An ethical stakeholder approach to crisis communication: A case study of Foxconn's 2010 employee suicide crisis. Journal of Business Ethics, 117(2), 371-386.

Zhang, J. (2010). Employee orientation and performance. An exploration of the mediating role of customer orientation. Journal of Business Ethics, 91, 111-121. 